\title{
EDUCAÇÃO FÍSICA NA ESCOLA UM MEIO PARA SE EDUCAR
}

\author{
Gleison Rodrigues Ribeiro ${ }^{1}$; Carmen Lúcia Dias ${ }^{2}$; Anderson dos Santos Carvalho ${ }^{3}$ \\ Universidade do Oeste Paulista - UNOESTE. ${ }^{1}$ Mestrado em Educação, Presidente Prudente - SP. ${ }^{2}$ Programa de Pós- \\ Graduação, Presidente Prudente - SP. E-mail: tiogleison@hotmail.com \\ ${ }^{3}$ Faculdade de Presidente Venceslau - FAPREV.
}

\section{RESUMO}

O objetivo do trabalho é apresentar a contribuição da Educação Física escolar como subsídio intrínseco no desenvolver do educar rumo ao encontro da emancipação e desenvolvimento humano, pois ela tem várias vertentes que se-pode utilizá-la para desenvolver uma educação mais justa, crítica, social, humana e coletiva. A metodologia empregada apresentou abordagem qualitativa de caráter bibliográfico. Acreditamos que a Educação Física bem orientada pode articular e desenvolver uma melhor sociedade. A intenção é utilizar está disciplina como instrumento para desenvolver uma sociedade mais justa, humana e emancipada. Entende-se que a Educação Física pode-se desenvolver um olhar mais crítico do aluno depende de como o professor irá trabalhar a sua aula.

Palavras-chave: Educação Física. Emancipada. Professor.

\section{PHYSICAL EDUCATION IN SCHOOLS A MEANS TO EDUCATE}

\begin{abstract}
The goal of working is to present the contribution of physical education through ways for free going and human development, because it has many ways that can be used to develop a better education, social, human, collective and critical. One of the ways that we mill relate in this work is physical education in its education context. The education together with physical education they can cambine, develop and make a better society. The intention is to use education and physical education as instruments to develop a free human and correct society. Its knowem that physical education can develop a crictical out look os the student, depending on how the teacher will work its class.
\end{abstract}

Key words: Physical Education. Emancipated.Teacher. 


\section{INTRODUÇÃO}

A educação e a Educação Física são instrumentos que podem ser utilizados para desenvolver uma melhor sociedade, que seja mais justa, crítica, social, humana e coletiva, com esses pressupostos a intenção é desenvolver uma sociedade mais emancipada.

A educação escolar é fundamental para o desenvolvimento humano, econômico, social, cultural e político de um país. Sendo assim a escolarização e a educação é um direito do cidadão e um patrimônio da sociedade devendo ser desenvolvida, planejada num contexto democrático e respeitando a sociedade.

A educação enquanto processo social permanente ocorre também fora do contexto escolar, por isso a escolha por espaços não formais de educação, não se limita ao âmbito da escola. A educação formal tem uma proposta pedagógica a seguir, de modo a formar os sujeitos para a cidadania, justiça, liberdade, igualdade e identidade coletiva, fundamentando-se na solidariedade (GOHN, 2006).

As escolas juntamente com os espaços da cidade podem contribuir para a formação plena dos indivíduos promovendo debates, discussões e eventos que fomentem a participação delas juntamente com os demais cidadãos (GADOTTI, 2002).

Os recursos fundamentais para as pessoas seriam a informação, o conhecimento e a capacidade de produzi-los e manejá-los. A educação é entendida como uma atividade por meio da qual se produz e se distribui conhecimento (TEDESCO, 1995).

A Educação Física na escola deve utilizar seus conteúdos como um instrumento de intervenção na aula, sendo assim pode colaborar para o pleno desenvolvimento das capacidades motrizes e expressivas do indivíduo, além de representar um meio para desenvolver contextualização entre os sujeitos.

O objetivo traçado para o estudo foi apresentar a contribuição da Educação Física escolar como subsídio intrínseco no desenvolver do educar rumo ao encontro da emancipação e desenvolvimento humano.

\section{METODOLOGIA}

Para tanto, a metodologia empregada foi analisar o conteúdo da Educação Física no âmbito escolar em duas dimensões; educação no contexto geral e a contribuição da disciplina como subsídio de colaborar com

educação no desenvolvimento dos sujeitos. A etapa da pesquisa consistiu em uma revisão bibliográfica sobre o tema e a importância de utilizar os conteúdos da Educação Física como um 
subsídio para complementar o desenvolvimento integral do aluno rumo a emancipação. Após o levantamento bibliográfico foi realizado análises sobre os textos, discussão sobre o tema, caracterizando assim uma pesquisa de cunho qualitativo. Segundo Minayo (2007), a pesquisa qualitativa:

[...] responde a questões muito particulares. Ela se ocupa, nas Ciências Sociais, com um nível de realidade que não pode e não deve ser quantificado. Ou seja, ela trabalha com o universo dos significados, dos motivos, das aspirações, das crenças, dos valores e das atitudes. (MINAYO, 2007, p. 21).

Em concordância com as colocações de Minayo (2007) acreditamos ser a abordagem qualitativa a melhor maneira de se proceder ao longo do caminho no presente estudo, tendo o propósito de discutir e apresentar aos alunos futuros professores em como utilizar a Educação Física como instrumento para desenvolver uma sociedade mais critica e emancipada.

\section{A Escola e o Professor}

Para que possa desenvolver-se uma educação emancipada, é fundamental argumentar pouco sobre a instituição escola, pois é por meio dela que se desenvolve a educação formal, uma educação mais dirigida e mais objetiva.

Segundo Saviani (2007), a escola é um instrumento de hegemonia, portanto precisa utilizála para desenvolver a consciência contra o grupo dominante, ela pode desenvolver um papel que auxilia o sujeito por meio da educação. É necessário que a escola contribua com desenvolvimento intelectual e cultural dos alunos para que estes sejam mais críticos, reflexivos e autônomos.

De acordo com Santos (2003), a cidadania é constituída por diferentes tipos de direitos e instituições; é produto de histórias sociais diferenciadas protagonizadas por grupos sócias diferentes.

Segundo Santos (2003), a sociedade liberal é caracterizada por uma tensão a existência individual, o mecanismo regulador dessa tensão é o princípio da cidadania que por um lado limita os poderes dos estados e por outro universaliza e equaliza as particularidades dos sujeitos de modo a facilitar o controle social das suas atividades e, conseqüentemente, a regulação social.

Segundo Silvestre e Custódio (2004), em 13 de julho de 1990 foi sancionado pelo Presidente da República, tornando Lei Federal n 8069 de 13 de julho 1990, o Estatuto da Criança e do Adolescente - ECA. O que deu base para essa lei foi o caput do art. 227 do texto constitucional que elenca um amplo conjunto de direitos disposto que: 
É dever da família, da sociedade e do Estado assegurar à criança e ao adolescente, com absoluta prioridade, o direito à vida, à saúde, à alimentação, à educação, ao lazer, à profissionalização, à cultura, à dignidade, ao respeito, à liberdade e a convivência familiar e comunitária, além de colocá-los a salvo de toda forma de negligência, discriminação, exploração, crueldade e opressão (COSTA, 1995, p. 27).

Para que os sujeitos adquirem esses direitos o professor deve agir como um estimulador e orientador da aprendizagem, sendo a reflexão sobre a sua prática que irá permitir a elaboração de novas formas de ensinar ou resolver problemas de aprendizagem dos seus alunos, tornando a ação pedagógica mais coerente, mais lúdica, mais justa, mais humana (SAVIANI, 2007).

Portanto, concordamos com as idéias de Pimenta (2000), quando diz que o/a professor/a apresenta e necessita de uma autonomia didática que se expressa no cotidiano de seu trabalho, pois só assim é capaz de enfrentar os desafios do processo ensino aprendizagem e da educação.

\section{Educação Física e suas Contribuições}

Afirma Müller e Rodrigues (2002), a Educação Física pode ser definida como prática de intervenção política pedagógica que tem como uma de suas finalidades básicas a orientação pedagógica para o desenvolvimento de atividades definidas como elementos expressivos da cultura corporal.

Segundo Mattos e Neira (2008), a Educação Física pode-se, então estabelecer o seguinte raciocínio: sendo movimento voluntário o foco das atividades proporcionadas nas aulas, a escolha do conteúdo deverá privilegiar, basicamente, elementos significativos para o grupo de alunos que irá desenvolver a aula. A Educação Física tem várias vertentes que podem contribuir para educação do movimento e também por uma educação pelo movimento. O professor pode utilizar dos seus conteúdos como; esportes, danças, lutas, brincadeiras, jogos, expressão corporal, atividades rítmicas, expressivas e conhecimento sobre o corpo, para auxiliar o aluno em sua educação em busca de uma emancipação.

O professor de Educação Física deve estar preocupado com uma educação progressista, para isso no momento em que o docente for planejar a sua aula este deve se perguntar: que conteúdos podem ajudar o aluno a desenvolver concepções de valores, conhecimentos, criticidade, criatividade para que o aluno possa ser um sujeito participativo na sociedade? Como a educação e Educação Física pode contribuir para esses aspectos serem desenvolvidos? (GHIRALDELLI JR, 2007). 
O ensino precisa estar comprometido com a compreensão crítica da realidade por meio dos conhecimentos e habilidades que transmitem. Assim o professor pode utilizar dos conteúdos da Educação Física para contribuir para o exercício de uma prática social, menos alienante, mas que visa uma emancipação dos alunos.

Quando se pronuncia em uma prática de intervenção em busca da emancipação na Educação Física é importante apresentar os conteúdos da Educação Física revolucionária, está propõe conteúdos que servem de subsídios para emancipação dos indivíduos.

De acordo com Medina (1996) a Educação Física Revolucionária é a concepção mais ampla. Procura interpretar a realidade de uma forma dinâmica e dentro da sua totalidade. Os fenômenos nessa concepção são considerados de maneira global e não isolados. O ser humano é entendido como um todo por meio de suas dimensões e no conjunto de suas relações com os outros e com o mundo. Sendo assim essa concepção está aberta as contribuições das ciências, procurando sempre primar pela autenticidade e coerência, ainda que compreenda as dificuldades inerentes às contradições da sociedade. Essa concepção considera o corpo em todas as suas manifestações e significações, não sendo apenas a parte do homem, mas o próprio homem. Assim é possível entender a Educação Física como uma educação de movimentos e ao mesmo tempo uma educação pelo movimento. Para isso a educação do movimento não pode comprometer os valores mais humanos, compreendendo o próprio esporte de alto nível, este pode ser considerado um ato educativo em busca de uma emancipação.

A Educação Física Revolucionária pode ser definida como a arte e a ciência do movimento humano que, por meio de atividades específicas, auxiliam no desenvolvimento integral dos seres humanos, renovando-os e transformando-os no sentido de sua auto-realização e em conformidade com a própria realização de uma sociedade justa e livre (MEDINA, 1996, p. 81,82).

Os profissionais que se apropriaram da Educação Física Revolucionária são, portanto, verdadeiros agentes de renovação e transformação da sociedade. Sendo assim compreendem os determinismos e condicionamentos, desta forma são capazes de agir sobre eles. Esses profissionais consideram a unidade entre o pensamento e a ação, lutando em defesa de uma educação que visa verdadeiramente à liberdade. Os profissionais que se apropriam dessa concepção não podem deixar de serem políticos. É preciso enxergar os problemas da Educação Física à luz do contexto histórico-cultural (sociopolítico-econômico) mais amplo. É preciso ter uma visão mais ampla desses aspectos para o crescimento humano. Para transcender as superficialidades dos fenômenos é preciso desenvolver o diálogo em favor da transformação no sentido mais humano. 
Mattos e Neira (2008), diz que a aula deve conduzir o aluno à superação de conflitos grupais e individuais. Sendo assim podem-se oferecer situações problemas por meio de questionamentos. Portanto, a aula de Educação Física deve escapar da mera repetição de movimentos tidos como ideais ou adequados, para uma aula mais inteligente, mais bem elaborada num ensino construtivo.

Um professor bem subsidiado possui uma clara noção do seu papel político como formador de cidadãos que se constituem em sujeitos do processo de aprendizagem, desta forma o professor não deverá limitar sua formação aos saberes específicos que a educação e a Educação Física podem contribuir para uma melhor sociedade.

\section{CONCLUSÃO}

A Educação Física tem instrumentos que podem desenvolver uma melhor sociedade que seja mais justa, crítica, social, humana e coletiva. Acredita-se que esses pressupostos podem ser desenvolvidos com um olhar crítico da escola, do professor e uma atitude mais coerente conforme a realidade do aluno, dessa maneira a instituição escola, junto com a educação e a disciplina de Educação Física por meio dos seus conteúdos podem apresentar subsídios para desenvolver uma sociedade mais humana e emancipada.

\section{REFERÊNCIAS}

COSTA, A.C.G. De menor a cidadão. 1 ed. Brasília: Ministério da ação social, 1995.

GADOTTI, M. et al. Cidade educadora: princípios e experiências. São Paulo: Cortez, 2002.

GOHN, M. G. Educação não-formal, participação da sociedade civil e estruturas colegiadas nas escolas. Ensaio: Avaliação e Políticas Públicas em Educação, Rio de Janeiro, v. 14, n. 50, p. 27-38, jan./mar. 2006.

GHIRALDELLI JR. P. Educação Física progressista: A pedagogia crítico-social dos conteúdos e a educação física brasileira. 10 ed. São Paulo: Loyola, 2007.

MATTOS, G. M.; NEIRA, M. G. Educação Física infantil: construindo movimento na escola. 7. ed. São Paulo: Phorte, 2008.

MEDINA, J. P. S. A Educação Física cuida do corpo e "mente". 14. ed. Campinas: Papirus, 1996.

MINAYO, C.S. (org.). Pesquisa Social: teoria, método e criatividade. 25a Ed. Ver e atualizada. Petropoles, RJ: Vozes, 2007.

MÜLLER, V. R.; RODRIGUES, P. C. Reflexões de quem navega na educação social: uma viagem com crianças e adolescentes. Maringá: Clichetec, 2002. 
PIMENTA, S. G. Saberes pedagógicos e atividade docente. 2. ed. São Paulo: Cortez, 2000.

SANTOS, B. S. Pela mão de Alice: o social e o político na pós-modernidade. 3.ed. São Paulo: Cortez, 2003.

SAVIANI, D. Escola e democracia. 39. ed. Campinas: Autores Associados, 2007.

SILVESTRE, E.; CUSTÓDIO, S. S. D. Os direitos infanto-juvenis: aspectos políticos e jurídicos para a sua caracterização. Maringá: Editora UEM, 2004.

TEDESCO, J. C. O novo pacto educativo: educação, competitividade e cidadania na sociedade moderna. São Paulo: Ática, 1995. 